\title{
ARTICLE
}

Clinical research

\section{Investigation of the long-term sustainability of changes in appetite after weight loss}

\author{
$\mathrm{S} \mathrm{Nymo}^{1,2} \cdot \mathrm{SR}$ Coutinho $^{1} \cdot \mathrm{PH}_{\text {Eknes }}{ }^{1} \cdot$ I Vestbostad $^{1} \cdot \mathrm{JF}$ Rehfeld $^{3} \cdot$ H Truby $^{4} \cdot$ B Kulseng $^{1,2} \cdot$ C Martins $^{1,2}$
}

Received: 23 August 2017 / Revised: 23 April 2018 / Accepted: 30 April 2018 / Published online: 21 June 2018

(c) The Author(s) 2018. This article is published with open access

\begin{abstract}
Background/Objective Diet-induced weight loss (WL) leads to a compensatory increase in appetite and changes in the plasma concentration of appetite-regulating hormones are likely to play a role. Whether these changes are transient or sustained remains unclear. This study aimed to assess if changes in subjective and objective appetite markers observed with WL are sustained after 1 year $(1 \mathrm{Y})$.

Subjects/Methods In total 100 (45 males) individuals with obesity (BMI: $37 \pm 4 \mathrm{~kg} / \mathrm{m}^{2}$, age: $43 \pm 10$ years) underwent 8 weeks (wks) of a very-low energy diet (VLED), followed by 4 wks refeeding, and a 1Y maintenance program. Fasting/ postprandial subjective ratings of hunger, fullness, desire to eat, and prospective food consumption (PFC) were assessed, and plasma concentration of active ghrelin (AG), total peptide YY (PYY), active glucagon-like peptide 1, cholecystokinin (CCK), and insulin measured, at baseline, week 13 (Wk13) and 1Y.

Results At Wk13, 16\% WL $(-18 \pm 1 \mathrm{~kg}, P<0.001)$ was associated with a significant increase in fasting and postprandial hunger ratings $(P<0.01$ and $P<0.05$, respectively), and postprandial fullness $(P<0.01)$ combined with a reduction in PFC $(P<0.001)$. These were accompanied by a significant rise in basal and postprandial AG concentrations $(P<0.001$, for both $)$, a reduction in postprandial CCK $(P<0.01)$ and in basal and postprandial insulin $(P<0.001)$. At $1 \mathrm{Y}$ follow-up, with sustained WL $(15 \% ;-16 \pm 1 \mathrm{~kg}, P<0.001)$, fasting hunger and postprandial fullness ratings remained increased $(P<0.05$ for both), and postprandial PFC reduced $(P<0.001)$. Basal and postprandial AG remained elevated and insulin reduced $(P<$ 0.001 , for all), while postprandial CCK was increased $(P<0.01)$ and PYY decreased $(P<0.001)$.

Conclusion With a $15 \%$ sustained WL at $1 \mathrm{Y}$, the drive to eat in the fasting state is increased, but this may be balanced out by raised postprandial feelings of fullness. To assist with WL maintenance, new strategies are required to manage increased hunger and drive to eat.
\end{abstract}

Electronic supplementary material The online version of this article (https://doi.org/10.1038/s41366-018-0119-9) contains supplementary material, which is available to authorized users.

$\triangle$ S Nymo

siren.nymo@ntnu.no

1 Obesity Research Group, Department of Cancer Research and Molecular Medicine, Faculty of Medicine, Norwegian University of Science and Technology (NTNU), Trondheim, Norway

2 Centre for Obesity and Innovation (ObeCe), Clinic of Surgery, St. Olav University Hospital, Trondheim, Norway

3 Department of Clinical Biochemistry, Rigshospitalet, University of Copenhagen, Copenhagen, Denmark

4 Department of Nutrition, Dietetics \& Food, Monash University, Melbourne, Australia

\section{Introduction}

Worldwide $>40 \%$ of all adults have attempted to control their body weight by weight loss strategies [1]. Weight loss (WL) maintenance is now the most challenging part within obesity management as relapse is common and only 10-20\% succeed in maintaining their lower body weight long-term [2,3]. Reasons for recidivism are poorly understood and likely to be complex, involving a combination of reduced motivation and compliance to restrict energy intake by dieting and increase energy expenditure via exercise regimens [4-7], together with metabolic, neuroendocrine and autonomic adaptive responses that oppose the reduced obese state [8-11].

The landmark papers by Leibel et al. [10] and Dulloo et al. [11] showed that WL is followed by a reduction in total energy expenditure (TEE) larger than predicted and, 
despite that, an increase in hunger and hyperphagia. Since then, reviews by Cornier et al. [8], Rosenbaum et al. [9] and Doucet et al. [12], among others, have described the compensatory mechanisms activated with WL, on both sides of the energy balance equation, which may contribute to weight re-gain.

A recent study has estimated that the increased appetite seen with WL is probably threefold larger than the corresponding reduction in TEE and likely the main driver of weight re-gain [13]. Several studies, that use visual analogue scales (VAS) to measure appetite, demonstrate that dietinduced WL, outside of ketosis, is associated with increased hunger feelings in the fasted state [14-16], likely mediated via an increase in plasma ghrelin concentration [15-17], even though some studies report no change $[18,19]$. The impact of WL on fullness feelings $[15,16,20]$ and secretion of peptides signalling satiety is, unfortunately, less clear $[15,16,20,21]$.

Whether the changes in appetite associated with WL are sustained in the long-term remains a point of debate, as the available research is inconsistent in its findings [15, 20, 21], with different methods to measure appetite being employed and different hormonal fractions being measured. Sumithran et al. [15] reported a sustained increase in subjects feelings of hunger using VAS, plus an increase in ghrelin plasma concentration at 1 year follow-up, as well as no change in postprandial concentration of active glucagon-like peptide 1 (GLP-1) and a reduction in total peptide YY (PYY), after an initial $12 \%$ WL followed by $50 \%$ regain. However, another study reported a sustained increase in both total GLP-1 and $\mathrm{PYY}_{3-36}$ postprandial secretion after a $12 \%$ sustained WL at 1 year follow-up [21], while another showed no change in active GLP-1 postprandial secretion after 6 months of sustained WL maintenance [20]. Moreover, from our knowledge, no study has determined if sex modulates the changes in appetite seen with WL. This is of great importance given that sex has been shown to modulate appetite sensations and the secretion of several appetite-related hormones [22, 23]. The primary aim of this study was to determine if changes in appetite (both subjective feelings of appetite using VAS and objective plasma concentrations of appetite-related hormones) seen after WL, are sustained at 1-year (1Y) follow-up. A secondary aim was to determine if sex modulates any changes in appetite.

\section{Methods}

\section{Participants}

Healthy adults with obesity $\left(30<\mathrm{BMI}<50 \mathrm{~kg} / \mathrm{m}^{2}\right.$ ) from the local community of Trondheim, Norway, were recruited for this study by social media and articles in the local newspaper. The study was approved by the regional ethics committee (Ref., 2012/1901), registered in ClinicalTrial. gov (NCT01834859) and conducted according to the Declaration of Helsinki. All participants signed informed consent before participation.

Participants had to be weight stable $(<2 \mathrm{~kg}$ change over the last 3 months), not dieting to lose weight and with a sedentary lifestyle. Exclusion criteria were pregnancy, breast-feeding, clinical significant illness, including diabetes, previous WL surgery and/medication known to affect appetite/metabolism or induce WL.

\section{Study design}

This was a longitudinal intervention study with repeated measurements. Participants underwent an 8-week supervised very-low energy diet (VLED), followed by a 4-week refeeding phase, and a 1-year weight maintenance program (study diagram, Supplementary Figure I).

\section{Weight loss phase}

Participants followed for 8 weeks a VLED (Allévo, Karo Pharma AS, Sweden) with $550 / 660 \mathrm{kcal} /$ day, for females and males respectively (carbohydrate $42 \%$, protein $36 \%$, fat $18 \%$ and fibre $4 \%$ ), plus no-energy fluids and low starch vegetables ( $\max 100 \mathrm{~g} /$ day) [16].

At week 9, participants were gradually reintroduced to normal foods, while withdrawing from the VLED products. An individual diet plan (estimated energy requirements (Ereq) at Wk9: $1690 \pm 407 \mathrm{kcal} /$ day) was prescribed by a trained dietician tailored to individual energy requirements (measured resting metabolic rate (RMR; Wk9 (1339 \pm 252 $\mathrm{kcal} /$ day $) \times($ physical activity level $(\mathrm{PAL}))$ (extracted from individual physical activity monitors (BodyMedia ${ }^{\circledR}$, SenseWear, Pittsburgh, USA), with $15-20 \%$ protein, 20-30\% fat, and $50-60 \%$ carbohydrate, aimed at weight stabilisation [24]. VLED products ceased at the end of week 10.

Participants were asked not to change their PA levels during this phase of the study. To check for compliance, participants wore SenseWear armbands for 7-days at baseline and at weeks 9 and 13 (Wk9 and Wk13). Data were considered valid if the participants wore the device for $\geq 4$ days, including at least 1 weekend day and $>95 \%$ of the time [25].

\section{Weight maintenance phase}

A $1 \mathrm{Y}$ follow-up program aimed at WL maintenance was offered from Wk13. The diet plan provided at week 9 was revised at week 13 by a trained dietician having into account individual energy requirements (measured RMR $(1584 \pm 285 \mathrm{kcal} /$ day $) \times \mathrm{PAL}$ at $\mathrm{Wk} 13)$ and designed for 
weight maintenance (Ereq at Wk13: $2088 \pm 520 \mathrm{kcal} /$ day). The multidisciplinary follow-up program included regular individual and group based sessions, focusing on nutritional counselling, increased PA levels and cognitive behavioural therapy. A dietitian was present in all group meetings and participants had an individual consultation with a dietitian $(1 \mathrm{~h})$ every other month. Participants were also asked to wear SenseWear armbands at 6 and at 12 months to record PA levels.

\section{Data collection}

The following measurements were conducted at baseline, Wk13 and 1Y follow-up.

\section{Body weight and composition}

Air-displacement plethysmography (BodPod, COSMED, Italy) was used, while participants were in the fasting state.

\section{Appetite measurements}

Subjective appetite feelings (hunger, fullness, desire to eat (DTE) and prospective food consumption (PFC)) were measured with a $10-\mathrm{cm}$ visual analogue scale (VAS) [26], and blood samples for the analysis of appetite-related hormones (active ghrelin (AG), active glucagon-like peptide 1 (GLP-1), total peptide YY (PYY), cholecystokinin (CCK), and insulin) collected in fasting and every $30 \mathrm{~min}$ after a standardised breakfast (600 kcal: $17 \%$ protein, $35 \%$ fat, and $48 \%$ carbohydrate) for $2.5 \mathrm{~h}$. The breakfast consisted of 75 oat-bread (whole grain), $5 \mathrm{~g}$ butter, $40 \mathrm{~g}$ strawberry jam, 35 $\mathrm{g}$ cheese (38 $\mathrm{E} \%$ fat) and $250 \mathrm{ml}$ low fat (1.2 E\% fat) milk. The satiety quotient (SQ) for each appetite sensation, as well as an average estimate, was calculated at each assessment time point [27].

Plasma samples were analysed for AG, active GLP-1, total PYY, CCK and insulin using a Human Metabolic Hormone Magnetic Bead Panel (LINCOplex Kit, Millipore) and CCK using an" in-house" RIA method [28] (intra-and inter-assay CV were for AG, active GLP-1 and PYY $<10 \%$ and $<20 \%$; insulin $<10 \%$ and $<15 \%$ and $\mathrm{CCK}<5 \%$ and $<15 \%$, respectively. Blood was collected into EDTA-coated tubes. Around $1 \mathrm{ml}$ of full blood was then transferred into a micro tube and $20 \mu \mathrm{l}$ mixture of inhibitors $(10 \mu \mathrm{l}$ of Pefabloc (Roche Diagnostic, Germany) $+10 \mu$ DPP-IV (Merck Millipore, Germany)) added. For CCK analysis, aprotinin (DSM, Coatech AB, Kaiseraugst, Switzerland) $(500 \mathrm{KIU} / \mathrm{ml}$ whole blood) was added to the EDTA tube. Samples were then centrifuged at $3200 \mathrm{rpm}$ for $10 \mathrm{~min}$ at $18^{\circ} \mathrm{C}$ and the plasma frozen at $-80{ }^{\circ} \mathrm{C}$ until further analysis. Samples were analysed when all time points were available within the same participant (average 1 year). The analysis was performed by the same technician, except for CCK which was analysed at Prof. Rehfelds lab (Rigshospitalet, University of Copenhagen, Copenhagen, Denmark).

\section{Statistical analysis}

Statistical analysis was performed with SPSS version 22 (SPSS Inc., Chicago, IL), and data presented as mean \pm SEM, except for baseline anthropometric data at baseline, where mean \pm SD was used. Statistical significance was set at $P<0.05$. Data were analysed using linear mixed-effects models, with restricted maximum-likelihood estimation, including fixed effects for time and sex, and their interaction. Bonferroni correction was used for post hoc pairwise comparisons. Average values for appetite ratings and plasma concentrations of appetite-related hormones refer to the average of all time points (fasting and postprandial). Participants with data at $1 \mathrm{Y}$ were considered completers and kept in the analysis. All the analysis was done for completers, except for changes in body weight where an intention to treat analysis with baseline values carried forward was used. The Benjamini-Hochberg method, which controls for the false discovery rate [29] was used to adjust for the large number of outcome variables. The association between changes in subjective and objective appetite markers (both at Wk13 and 1Y), between the magnitude of WL (both at Wk13 and 1Y) and the respective changes in both subjective and objective appetite markers and between changes in appetite at $\mathrm{Wk} 13$ and $\mathrm{WL}$ maintenance at $1 \mathrm{Y}$ were investigated with Pearson or Spearmen correlation.

\section{Results}

\section{Participants}

In total 100 (55 females) participants fulfilled the study entry criteria and started the study. Of those, 95 participants completed the 8-week VLED ( 2 did not tolerate the VLED, 1 was excluded due to consumption of extra foods, 1 withdrew for personal reasons and 1 was lost to follow-up), 94 completed Wk 13 measurements (1 withdrew due to family illness) and 71 (41 females) completed the full $1 Y$ (8 withdrew due to own or family related illness, 3 due to work constraints making it difficult to return for measurements, 2 were excluded due to non-compliance as they had started a new VLED, and 10 were lost to follow-up).

Baseline characteristics of the participants who started and completed the study are presented in Table 1. There were no significant differences in any baseline measurement between those who completed and those who did not complete the study. Moreover, no differences were seen between completers and non-completers regarding changes 
Table 1 Baseline characteristics of the participants

\begin{tabular}{|c|c|c|c|c|c|c|c|}
\hline & \multicolumn{3}{|l|}{ All $(N=100)$} & \multicolumn{3}{|c|}{ Completers $(N=71)$} & \multirow[b]{2}{*}{$P$-value } \\
\hline & All $(N=100)$ & Males $(n=45)$ & Females $(n=55)$ & All $(N=71)$ & Males $(n=30)$ & Females $(n=41)$ & \\
\hline Age (year) & $42.5 \pm 9.7$ & $39.7 \pm 9.1$ & $44.8 \pm 9.7 * *$ & $43.4 \pm 9.4$ & $40.3 \pm 9.2$ & $45.6 \pm 9.0^{*}$ & 0.140 \\
\hline Weight $(\mathrm{kg})$ & $110.3 \pm 18.4$ & $120.1 \pm 19.6^{* * *}$ & $102.3 \pm 12.8$ & $109.1 \pm 18.7$ & $120.4 \pm 19.7 * * *$ & $100.9 \pm 12.9$ & 0.313 \\
\hline BMI $(\mathrm{kg} / \mathrm{m})$ & $36.7 \pm 4.2$ & $36.6 \pm 4.9$ & $36.7 \pm 3.5$ & $36.4 \pm 4.0$ & $36.6 \pm 4.7$ & $36.2 \pm 3.5$ & 0.274 \\
\hline FM \% & $44.1 \pm 6.4$ & $39.3 \pm 5.7$ & $47.9 \pm 3.9 * * *$ & $44.0 \pm 6.4$ & $39.2 \pm 6.2$ & $47.3 \pm 4.0 * * *$ & 0.849 \\
\hline
\end{tabular}

Values are mean \pm SD

$B M I$ Body-mass index (calculated as the weight in $\mathrm{kg}$ divided by the square of the height in metres). FM Fat mass

$P$-values are for comparisons between all participants and completers. Symbols denote significant differences between sexes in each group

$* P<0.05, * * P<0.01$ and $* * * P<0.001$

in appetite with WL (Wk13), even though completers lost more weight at Wk13 $(20.0 \pm 5.0$ vs $16.8 \pm 4.4 \mathrm{~kg}, P<$ $0.05)$. Females were older $(P<0.05)$, lighter $(P<0.001)$ and had a higher FM $(\%)$ than males $(P<0.001)$, but there was no difference in BMI between sexes.

No changes in total PA duration or time spent in light, moderate or vigorous activities were measured during the WL phase. Time spent in vigorous activities was significantly increased at 6 months in all participants and females $(P<0.01$ and $P<0.05$, respectively), but returned to baseline levels at $1 \mathrm{Y}$ for all groups. Steps/day were significantly increased at 6 months in all participants $(P<$ $0.01)$ and at $1 Y$ in males only $(P<0.05)$. See Supplementary Table 1.

\section{Body weight and composition}

Changes in body weight are reported in Fig. 1. Mean WL at Wk13 was $16 \%(-18 \pm 1 \mathrm{~kg})$, and this was maintained at 1Y follow-up in completers: $15 \% \mathrm{WL}(-16 \pm 1 \mathrm{~kg}, P<$ $0.001)$. The intention to treat analysis revealed an increase in body weight from $\mathrm{Wk} 13$ to $1 \mathrm{Y}$ in all participants $(6 \pm 1$ $\mathrm{kg}, P<0.001)$, but body weight at $1 \mathrm{Y}$ was still significant lower than baseline $(-11 \pm 1 \mathrm{~kg}, P<0.001)$.

FM (\%) was significantly decreased at Wk13 in all participants, males and females $(-9 \pm 1 \%,-11 \pm 1 \%$ and -7 $\pm 1 \%$, respectively, $P<0.001$ for all groups) and remained lower than baseline at $1 \mathrm{Y}(-9 \pm 1 \%,-9 \pm 1 \%$ and $-8 \pm$ $1 \%$, respectively, $P<0.001$ for all groups). The changes in absolute FM over time were not statistical significant different between sexes.

\section{Appetite feelings}

Hunger ratings in fasting were increased at $\mathrm{Wk} 13$ in all participants $(38 \%)$ and females $(P<0.01$ and $P<0.05$, respectively), and this was sustained at $1 \mathrm{Y}$ follow-up in all participants $(22 \%)(P<0.05)$. No significant change overtime were found for rating of fullness, DTE or PFC in

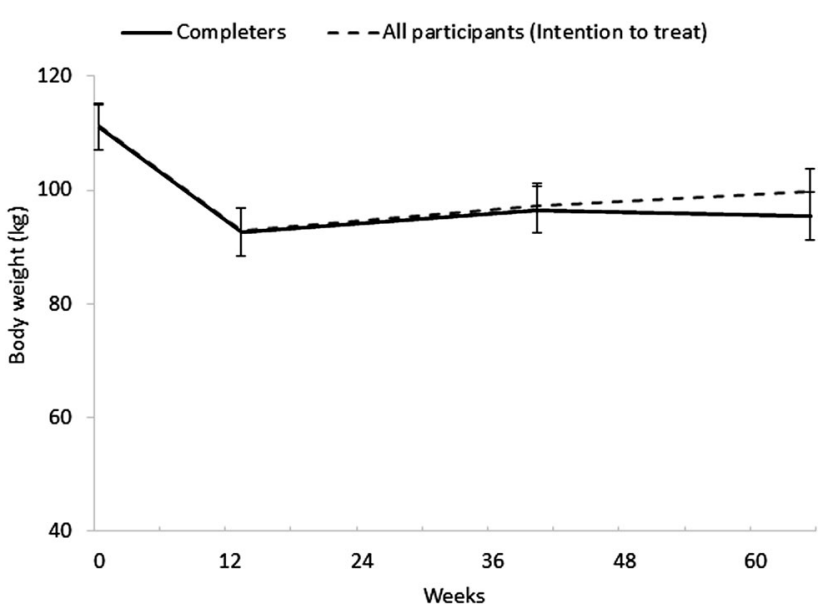

Fig. 1 Body weight in all participants (intention to treat analysis) and completers over time. Results presented as mean \pm SEM

fasting (see Fig. 2). Females had overall significant lower ratings of $\mathrm{PFC}$ in fasting than males $(5.4 \pm 0.2$ vs. $6.1 \pm 0.2$ cm, $P<0.05)$.

Mean ratings of hunger were significantly increased in all participants and males at Wk13 $(P<0.01$ and $P<0.05$, respectively) compared to baseline, but this was not sustained at $1 \mathrm{Y}$ follow-up. Mean fullness ratings were significantly increased in all participants $(10 \%)$ and males at Wk13 $(P<0.01$ and $P<0.05$, respectively), and this was sustained at $1 \mathrm{Y}$ follow-up in all participants $(6 \%)(P<$ $0.01)$, but not in males. Females, had a significant increase in mean rating of fullness at $1 Y$ follow-up only $(P<0.05)$. Mean ratings of PFC were significantly reduced in all participants and males at Wk13 $(P<0.001$ and $P<0.001$, respectively) and this was sustained at $1 Y$ follow-up $(P<$ 0.001, for both) (see Fig. 3). Females experienced a significant reduction in ratings of PFC at $1 \mathrm{Y}$ only $(P<0.05)$, and had significant lower overall rating of DTE $(2.3 \pm 0.2$ vs. $3.3 \pm 0.3 \mathrm{~cm}, P<0.05)$ and PFC $(3.4 \pm 0.3$ vs. $4.6 \pm 0.3$ cm, $P<0.01)$, compared to males. See Supplementary Table $2 \mathrm{~A}$. 
\All $\square$ Males $\square$ Females
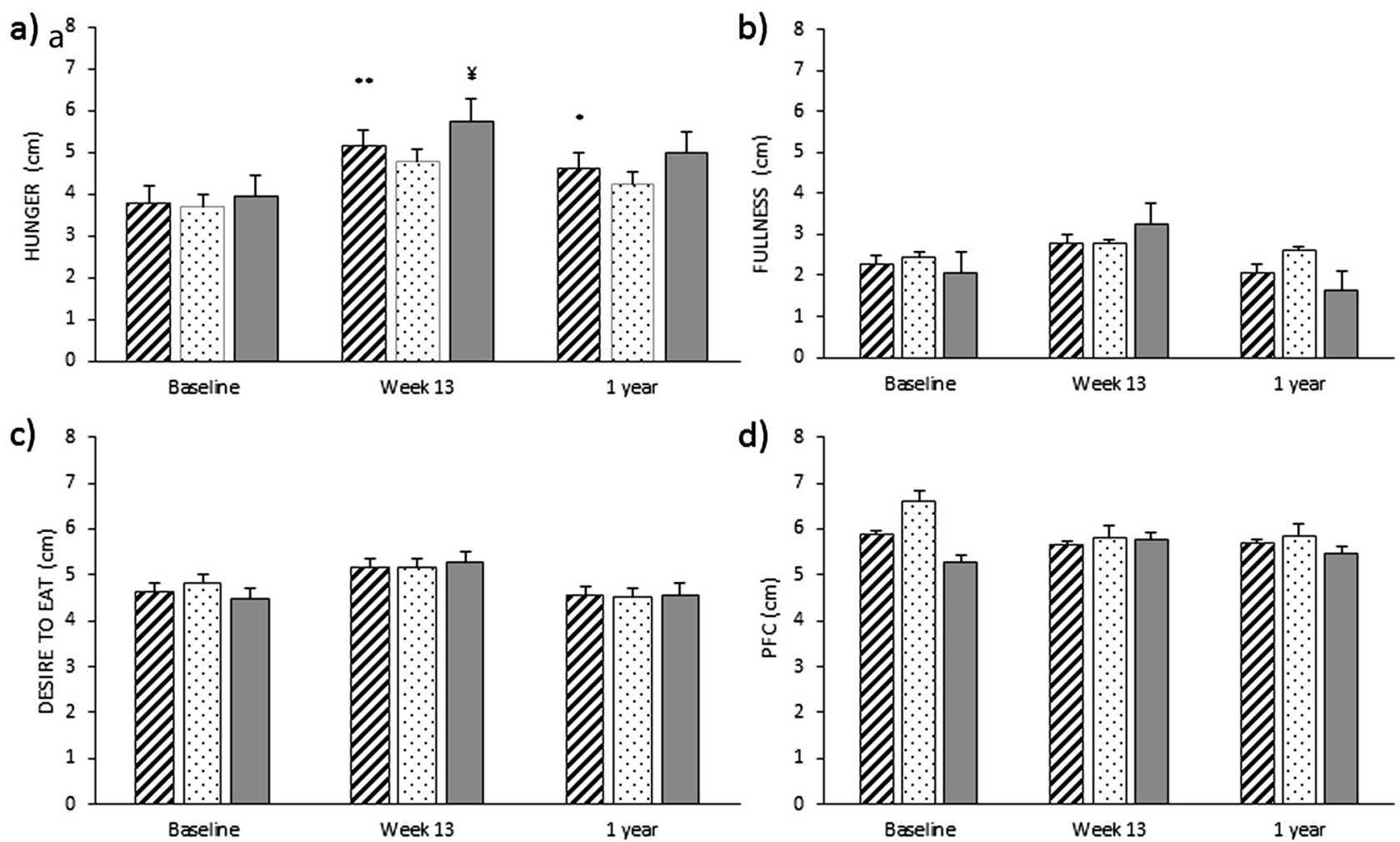

Fig. 2 Subjective feelings of hunger (a), fullness (b), desire to eat (c), and prospective food consumption (PFC) (d) in fasting, over time, in all participants, males and females. Results presented as estimated

marginal means \pm SEM. Symbols denote significant differences from baseline in all participants: ${ }^{* *} P<0.01$ and ${ }^{*} P<0.05$, and females: ${ }^{\sharp} P<$ 0.05
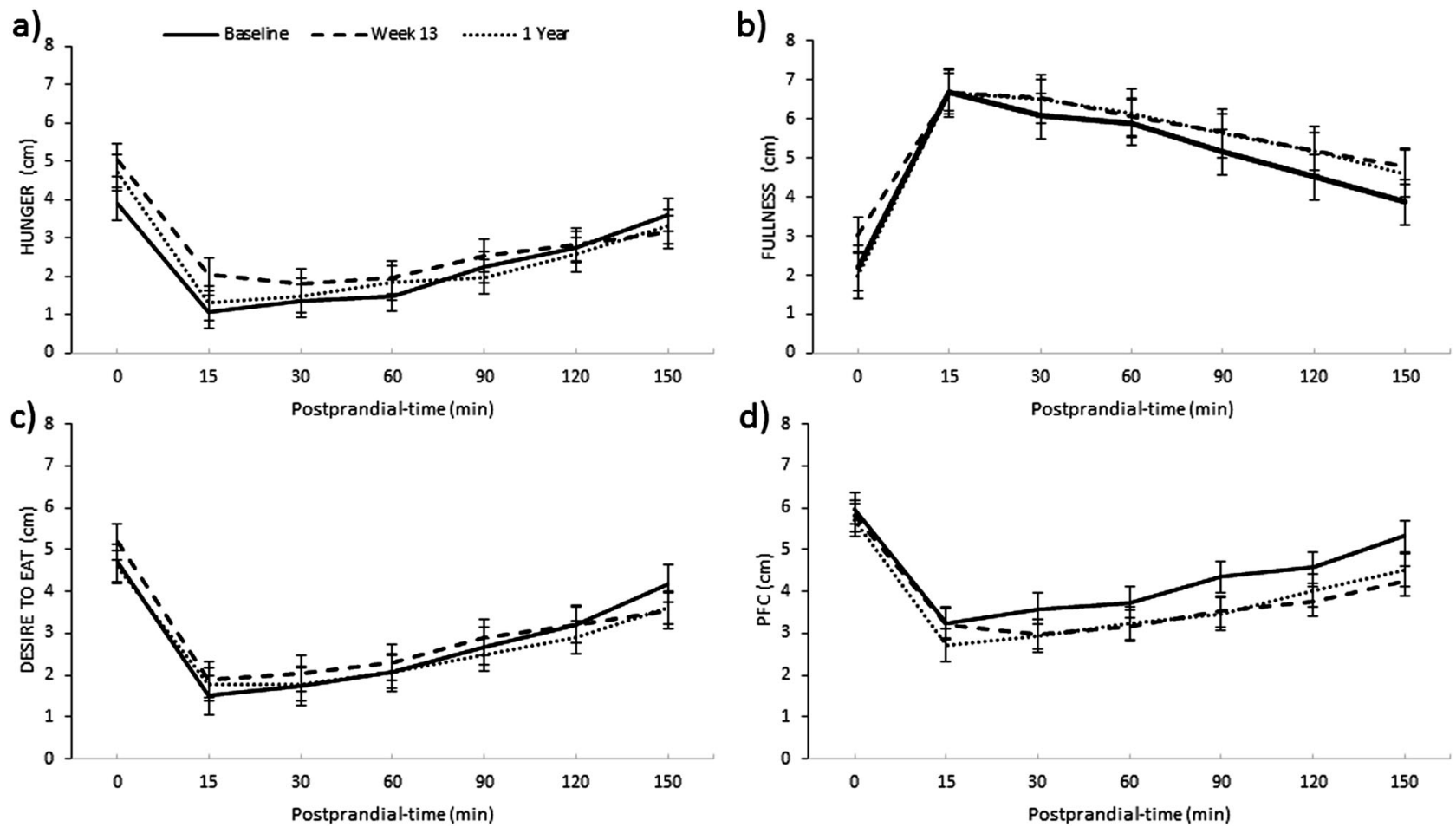

Fig. 3 Mean fasting and postprandial ratings of hunger (a), fullness (b), desire to eat (c), and prospective food consumption (PFC) (d) in

all participants over time. Results presented as estimated marginal means \pm SEM 
A significant increase in SQ hunger was seen at Wk13 and this was sustained at $1 \mathrm{Y}$ in all participants $(P<0.01$ and $P<0.05$, respectively) and females ( $P<0.05$, for both). See Supplementary Table 3.

\section{Appetite-related hormones}

Basal concentration of AG was significantly increased in all participants, males and females at Wk13 $(P<0.001, P<$ 0.001 , and $P<0.01$, respectively) and this was sustained at $1 Y$ follow-up $(P<0.001, P<0.01$, and $P<0.001$, respectively). Basal insulin concentration was significantly reduced in all participants, males and females at Wk13 $(P<$ $0.01, P<0.001$, and $P<0.01$, respectively) and this was sustained at $1 \mathrm{Y}(P<0.001$, for all groups $)$. Females had
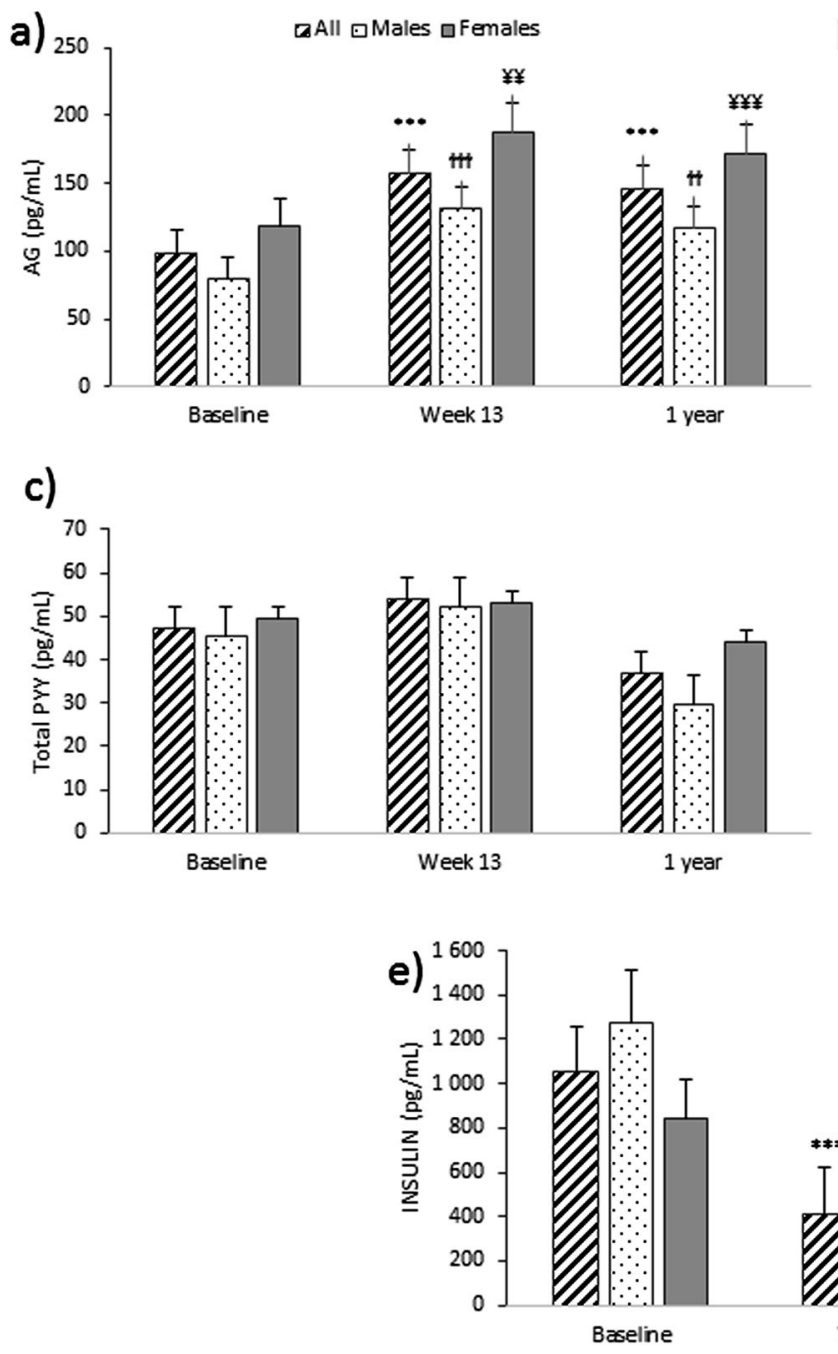

Fig. 4 Basal plasma concentrations of appetite-related hormones: active ghrelin (AG) (a), active glukagon like peptide-1 (GLP-1) (b), total peptide YY (total PYY) (c), cholecystokinin (CCK) (d) and insulin (e), over time in all participants, males and females. Results significant overall lower basal concentration of insulin (485 \pm 66 vs. $803 \pm 69$ pg/mL, $P<0.01$ ) than males (see Fig. 4 ).

Mean AG plasma concentration was significantly increased at Wk13 in all participants, males and females $(P$ $<0.001$, for all groups) and this was sustained at $1 \mathrm{Y}$ followup $(P<0.001$, for all groups). Mean total PYY concentration did not change significantly by $\mathrm{Wk} 13$, but was significantly lower than baseline at $1 \mathrm{Y}$ follow-up in all participants, males and females $(P<0.001, P<0.001$, and $P<0.01$, respectively). There was a significant reduction in mean CCK concentrations in all participants at Wk13 $(P<$ $0.01)$, but an increase at $1 Y$ follow-up, compared with baseline, in all participants and males $(P<0.01$, for both). There was a significant reduction in mean insulin concentration in all participants, males and females at $\mathrm{Wk} 13(P$ $<0.001$, for all groups), which was sustained at $1 \mathrm{Y}(P<$ b)
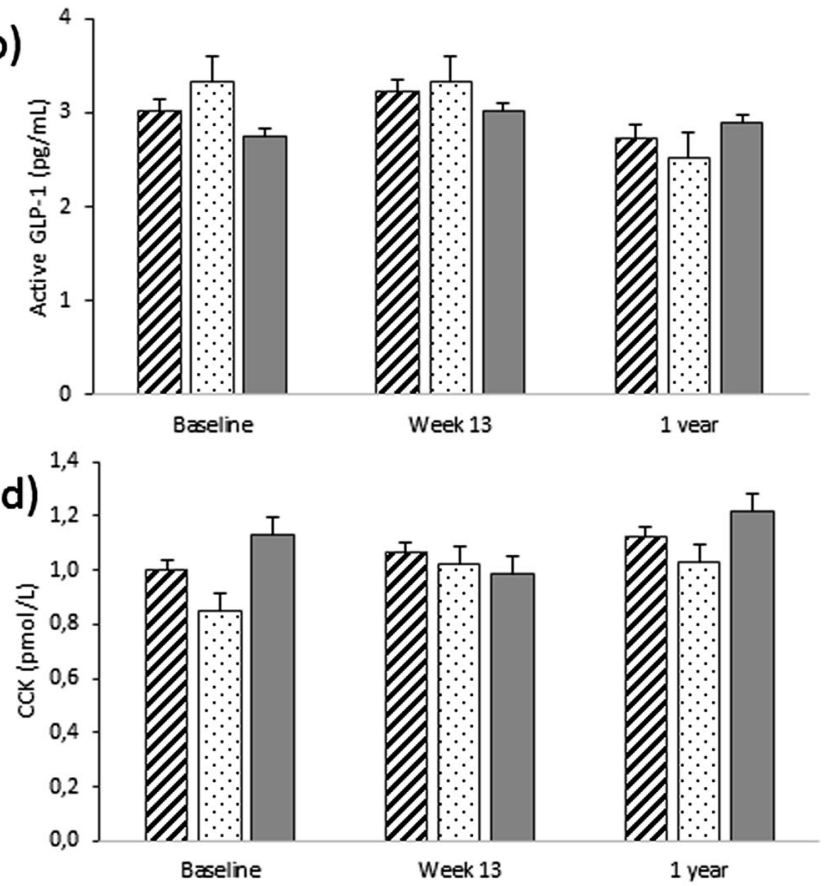

presented as estimated marginal means \pm SEM. Symbols denote significant differences from baseline in all participants: ${ }^{* * *} P<0.001$, males: ${ }^{\mathrm{m}} P<0.001$ and ${ }^{\mathrm{H}} P<0.01$ and females: ${ }^{¥ ¥} P<0.001$ and ${ }^{¥ ¥} P<$ 0.05 
0.001, for all groups) (see Fig. 5). See Supplementary Table 2B.

\section{Correlation analysis}

No significant correlation was found between changes in subjective appetite feelings and changes in the plasma concentrations of appetite-related hormones at any time point (either at W13 or $1 \mathrm{Y}$ ). The larger the WL at $1 \mathrm{Y}$, the larger was the increase seen in basal and postprandial concentration of AG $(r=-0.455$ and $r=-0.566$, respectively, $P<0.001$, for both). The opposite was seen for insulin, with a larger reduction in basal and postprandial insulin plasma concentrations as the magnitude of WL increased at $1 \mathrm{Y}(r=0.282$ and $r=0.277$, respectively, $P<$ 0.05 for both).
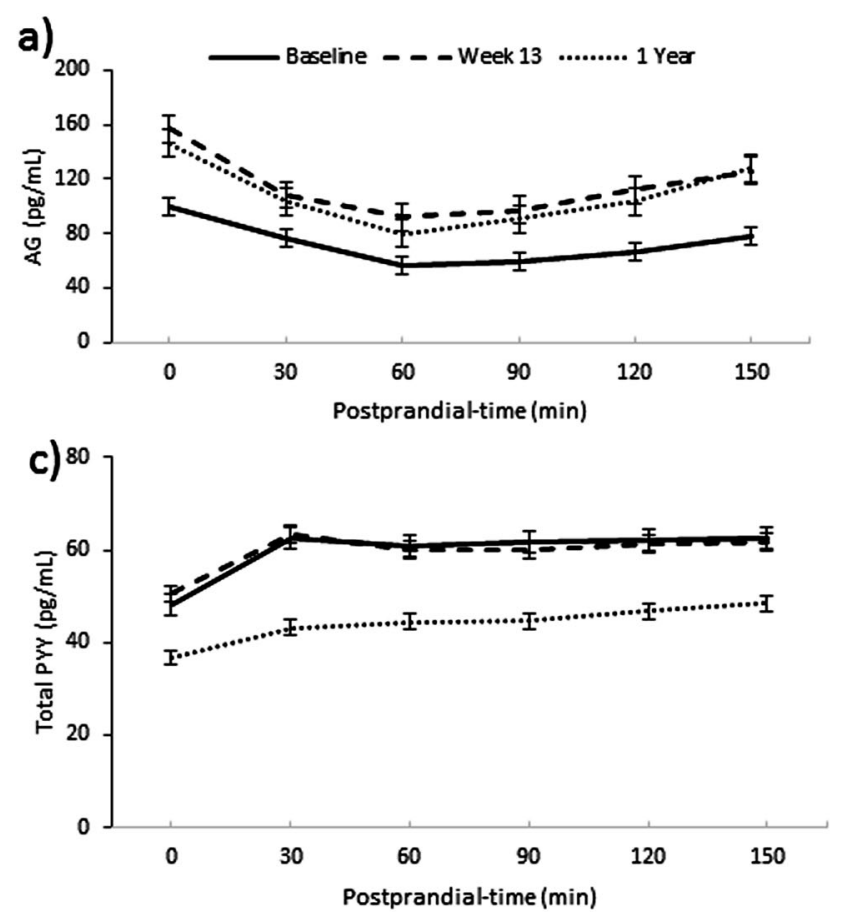
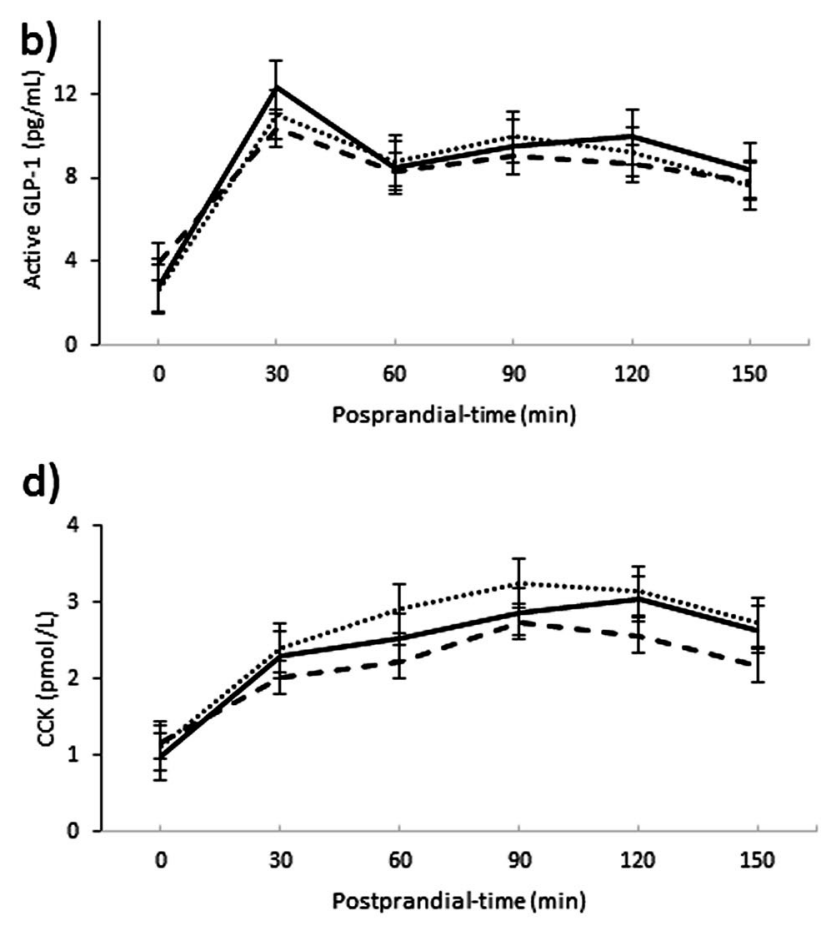

No significant association was found between the changes in appetite (namely increased hunger and AG plasma concentrations) seen with WL (Wk13) and WL maintenance/relapse at $1 \mathrm{Y}$.

\section{Discussion}

In this longitudinal study, a $16 \% \mathrm{WL}$ at $\mathrm{Wk} 13$ was sufficient to induce significant health benefits [30,31], and was associated with an increase in hunger, while postprandial feelings of fullness and SQ hunger were increased and PFC reduced. There was also a significant increase in basal and postprandial AG concentrations, a reduction in postprandial CCK and in basal and postprandial insulin. At $1 \mathrm{Y}$, and with sustained WL (15\%), fasting hunger, SQ hunger and

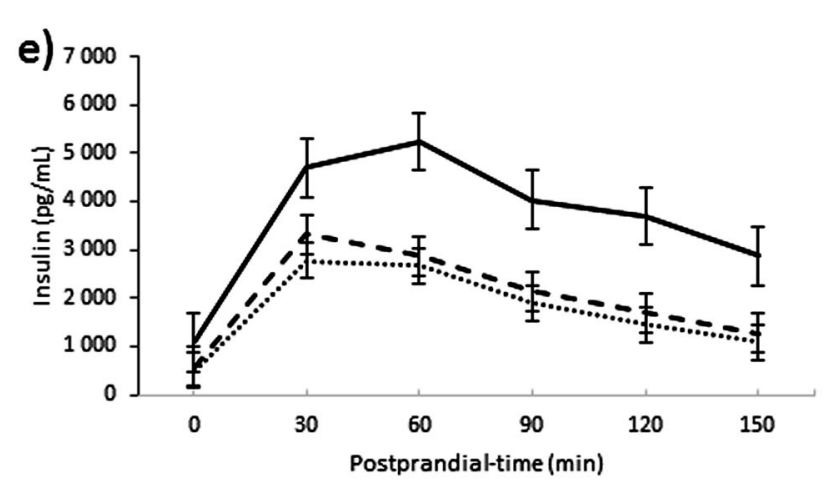

Fig. 5 Mean basal and postprandial plasma concentrations of appetiterelated hormones; a) active ghrelin (AG) (a), b) active glucagon-like peptide-1 (active GLP-1) (b), c) total peptide YY (total PYY) (c), d)
cholecystokinin(CCK) (d), and e insulin (e), for all participants over time. Results presented as estimated marginal means \pm SEM 
postprandial fullness ratings were still increased and postprandial PFC reduced. Basal and postprandial AG remained increased and insulin reduced, while postprandial CCK was increased and PYY decreased at 1Y follow-up, compared to baseline.

Few studies have been performed on the long-term sustainability of changes in appetite with WL and, to date, the results have been contradictory $[15,20,21]$. Sumithran et al. (2011) [15], in a similar longitudinal study, reported a sustained increase in postprandial hunger and DTE ratings, and AG plasma concentrations and a reduction in the postprandial concentration of total PYY and CCK at $1 Y$ follow-up [15]. However, the sample was composed of predominately post-menopausal women $(68 \%)$ and participants experienced an average $50 \%$ weight regain, after the initial 14\% WL. Iepsen et al. [21], using a similar study design, reported an increase in the plasma concentration of total ghrelin (both in the fasting and postprandial states), but surprisingly, an increase in total GLP-1 and PYY $3-36$ postprandial concentrations with a sustained $13 \% \mathrm{WL}$ at $1 \mathrm{Y}$ follow-up. Unfortunately, they did not measure changes in subjective feelings of appetite. Adam et al. [20], on the other hand, reported an increase in the postprandial concentrations of active GLP-1 after an $8 \%$ WL, which was not sustained after a 12-week WL maintenance period. The present study is the largest evaluating the impact of sustained WL maintenance, employing both subjective and objective appetite markers, and offers a perspective of sex being a mediator of outcome.

Even though ours and other studies tend to consistently show a sustained increase in subjective feelings of hunger, when using VAS, combined with an increase in ghrelin (either active or total) with long-term WL [15, 21], changes in postprandial fullness ratings and plasma concentrations of satiety peptides remain controversial [15, 21]. Differences in the magnitude of WL and its sustainability, hormonal fractions measured and methods of analysis of gut peptides [32-34] are likely to contribute to this inconsistent picture alongside most studies having mixed gender. Moreover, SQ hunger increased with WL, indicating a larger reduction in hunger after the same test meal, which is likely to reflect more accurate appetite sensation responses [35].

The increase in postprandial fullness with WL and WL maintenance is a novel. Sumithran et al. [15] reported no change in fullness either with a $14 \% \mathrm{WL}$ at Wk 10 or with a $7 \%$ WL maintenance at $1 Y$ follow-up in 34 overweight and obese individuals. Adam et al. [20] reported a similar outcome after an $8 \%$ WL, both acutely and after 12 weeks of WL maintenance in 32 overweight and obese individuals. Inconsistencies may be due to differences in the magnitude of WL, baseline participant characteristics and sample size. In our study, an initial 16\% WL was achieved, and this was sustained at $1 \mathrm{Y}(15 \% \mathrm{WL})$ in 71 obese individuals, which is a much larger WL and sample size compared with the other available studies [15, 20]. In a study by Delgado-Aros et al. [36], a higher BMI was associated with decreased postprandial fullness, which may explain why a so large WL, and concomitant BMI reduction, in our study led to increased fullness, when compared with baseline ratings. Even though studies on the impact of BMI on gastric capacity have not been consistent [37], a reduction in fasting gastric capacity has been reported after $\geq 5 \% \mathrm{WL}$ in individuals with obesity [38]. It remains speculative if changes in gastric capacity with WL contributed to increased postprandial fullness in the present study. Increased fullness after acute and sustained WL is unlikely to be explained by changes in CCK secretion, given that a reduction in $\mathrm{CCK}$ secretion was measured at $\mathrm{Wk} 13$, while an increase was seen with sustained WL at $1 \mathrm{Y}$ follow-up. Another explanation for the increased fullness with WL may be an increased postprandial secretion GLP-1 and PYY. Even though we saw no change in active GLP-1, and a reduction in total PYY plasma concentrations, others have shown that a large WL (14-15\%) leads to an increase in the

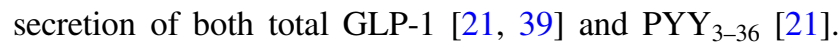
Finally, it is possible that increased fullness reflects the larger relative energy load of the test meal after WL.

To date, there is a dearth of information on the impact of WL on CCK plasma concentrations. The available evidence suggests that acute and rapid WL results in a reduction in postprandial concentrations of CCK [15, 40], which is consistent with our results, and probably reflects a lower stimulation due to less food (and fat) intake. It remains speculative why in the present study an increase in postprandial concentrations of CCK was seen with sustained WL at 1Y follow-up, while in Sumithran's study [15], with a similar design (8 weeks of VLED followed by refeeding and 1 year follow-up) and methodology (same RIA protocol for CCK analysis), a reduction was reported. However, due to continued dietetic support we achieved a $15 \%$ sustained WL at $1 Y$ follow-up, while Sumithran had a $50 \%$ weight regain, with only a $7 \% \mathrm{WL}$ at $1 \mathrm{Y}$ follow-up. This could have had an impact on CCK concentrations, and the increased postprandial CCK secretion may reflect a longterm adaptation to substantial WL, but that requires further substantiation.

The lack of association between subjective appetite feelings and the plasma concentration of appetite-related hormones seen in this study is not new [41, 42] and probably reflects the complexity of the appetite control system and the fact that changes in appetite feelings are unlikely to be attributable to alterations in a single hormone.

It has long been suggested that the increased hunger and reduced satiety seen after WL are part of a compensatory response that tries to bring body weight back to its set point 
[8, 43-45]. However, the findings from the present study: increased fasting hunger and basal AG plasma concentrations, as well as increased postprandial fullness, AG and CCK in response to large sustained WL may suggest otherwise. It is well known that obese individuals have lower plasma concentration of ghrelin in fasting [46] and a blunted postprandial secretion of total GLP-1 [39, 47], active GLP-1 [48], total PYY [48, 49], and CCK [50] and lower ghrelin postprandial suppression [46, 48]. Therefore, our overall findings, with the exception of PYY, could reflect a normalisation of appetite markers towards those seen in healthy-weight individuals. This is supported by Verdich et al. [39], who showed that postprandial total GLP-1 concentration increased after a $19 \mathrm{~kg}$ WL toward levels seen in a control normal-weight group. WL also leads to a reduction in TEE proportional to the new reduced body weight, even though some individuals may experience a larger than predicted reduction-a mechanism known as adaptive thermogenesis (AT) [10]. With, the exception of AT, which seems to occur in only some individuals, the changes in appetite and energy expenditure seen with WL could, therefore, be seen as a normalisation towards a lower body weight and not a compensatory mechanism that drives relapse. This new hypothesis is supported by the fact that neither us, nor Sumithran et al. [15] have reported any association between the changes in appetite seen with WL and long-term relapse at 1 year follow-up.

This study revealed several sex differences in the changes in appetite seen overtime with WL and WL maintenance. Hunger ratings in fasting were increased at Wk13 in females only, while mean postprandial ratings of hunger and fullness were significantly increased, and PFC reduced, in males only at Wk13, and postprandial fullness was increased in females only at $1 \mathrm{Y}$ follow-up. Moreover, mean postprandial CCK plasma concentrations did not change at any time point in females, while in males there was an increase at $1 \mathrm{Y}$ follow-up, compared to baseline. The fact that postprandial fullness was increased at $1 \mathrm{Y}$ follow-up in females only may reflect the fact that in males there was a tendency towards weight regain from Wk13 to $1 \mathrm{Y}$, while females continued to lose weight over time. More studies, with larger sample sizes and equal sex distribution, are needed to fully ascertain the potential modulating effect of sex on the changes in appetite seen with WL and WL maintenance and the explanatory mechanisms behind it.

This study has several strengths. First, it is the largest longitudinal study to examine changes in appetite with sustained WL. Second, it included both objective and subjective markers of appetite. Third, the participants were able to maintain their body weight at $1 \mathrm{Y}$ follow-up (compared with Wk13), probably due to on-going and tailored advice provided by dieticians. Finally, both males and females were included in the study in similar numbers. There are also some limitations. The multiplex assay used for the measurements of appetite hormones (except for CCK) is likely to result in less accurate and precise measurements compared with optimised assays for each individual hormone. The fact that the same type of test meal was given to all participants, regardless of their Ereq, constitutes a limitation. Females consumed a larger relative energy load compared with males and the same test meal represented a larger energy load with progressive WL. However, if we had adjusted the test meal accordion to Ereq (smaller meals in females compared with females and after WL) the appetite response would be blunted, because the nutrient stimuli would also be reduced, independently of the effect of sex or WL on appetite. This study was not powered to examine sex differences per se, so we are unable to draw firm conclusions about sex differences in responses to WL.

Our findings have some important practical implications. Patients with obesity who have lost and maintained significant amounts of weight via dieting, and benefited in terms of metabolic and overall health markers [30, 31], should expect a sustained increase in hunger feelings in the fasting state and to be prepared for these feelings to occur. This increased drive to eat in fasting may impact on food selection, eating rate and total energy intake, despite increased postprandial fullness, and thus lead to positive energy imbalance and increase the risk of weight regain. Health professionals working with this patient group, should be aware of the sustained increase in the drive to eat in the fasting state and help individuals develop management strategies to reduce the risk of overeating. However, the changes in appetite seen with WL (increased hunger and AG) were not associated with long-term relapse, which likely reflects the complexity of body weight regulation [51].

\section{Conclusions}

With a $15 \%$ sustained $\mathrm{WL}$ at $1 \mathrm{Y}$ follow-up, the drive to eat in the fasted state is increased, which may, despite increased postprandial fullness, drive overeating. Some sex differences were revealed, but larger studies are needed to support these findings. Future studies should evaluate if changes in appetite markers with WL are part of a compensatory response or a simple normalisation towards healthy-weight values, its relationship with actual food intake and its real impact on long-term WL maintenance.

Acknowledgements We thank all participants for their time and commitment, Hege Bjøru and Sissel Salater (at the ObeCe, Clinic of Surgery, St. Olav University Hospital) for support with screening and blood collection, Turid Follestad for helping with statistical analysis and Ingrid Hals for support with lab work (both at the Department of Cancer Research and Molecular Medicine, NTNU). 
Funding The Liaison Committee for education, research and innovation in Central Norway. Liaison Committee between the Central Norway Regional Health Authority (RHA) and the Norwegian University of Science and Technology (NTNU). Allevò, Karo Pharma AS. Sweden, for providing the VLED products (no commercial interest).

\section{Compliance with ethical standards}

Conflict of interest The authors declare that they have no conflict of interest.

Open Access This article is licensed under a Creative Commons Attribution 4.0 International License, which permits use, sharing, adaptation, distribution and reproduction in any medium or format, as long as you give appropriate credit to the original author(s) and the source, provide a link to the Creative Commons license, and indicate if changes were made. The images or other third party material in this article are included in the article's Creative Commons license, unless indicated otherwise in a credit line to the material. If material is not included in the article's Creative Commons license and your intended use is not permitted by statutory regulation or exceeds the permitted use, you will need to obtain permission directly from the copyright holder. To view a copy of this license, visit http://creativecommons. org/licenses/by/4.0/.

\section{References}

1. Santos I, Sniehotta FF, Marques MM, Carraca EV, Teixeira PJ. Prevalence of personal weight control attempts in adults: a systematic review and meta-analysis. Obes Rev. 2017;18:32-50.

2. Wing RR, Hill JO. Successful weight loss maintenance. Annu Rev Nutr. 2001;21:323-41.

3. Wing RR, Phelan S. Long-term weight loss maintenance. Am J Clin Nutr. 2005;82(1 Suppl):S222-5.

4. Kraschnewski JL, Boan J, Esposito J, Sherwood NE, Lehman EB, Kephart DK, et al. Long-term weight loss maintenance in the United States. Int J Obes. 2010;34:1644-54.

5. Anderson JW, Konz EC, Frederich RC, Wood CL. Long-term weight-loss maintenance: a meta-analysis of US studies. Am J Clin Nutr. 2001;74:579-84.

6. Robertson C, Archibald D, Avenell A, Douglas F, Hoddinott P, van Teijlingen E, et al. Systematic reviews of and integrated report on the quantitative, qualitative and economic evidence base for the management of obesity in men. Health Technol Assess. 2014;18:1-424.

7. Redman LM, Heilbronn LK, Martin CK, de Jonge L, Williamson DA, Delany JP, et al. Metabolic and behavioral compensations in response to caloric restriction: implications for the maintenance of weight loss. PLoS ONE. 2009;4:e4377.

8. Cornier MA. Is your brain to blame for weight regain? Physiol Behav. 2011;104:608-12.

9. Rosenbaum M, Leibel RL. Adaptive thermogenesis in humans. Int J Obes. 2010;34(Suppl 1):S47-55.

10. Leibel RL, Rosenbaum M, Hirsch J. Changes in energy expenditure resulting from altered body weight. $\mathrm{N}$ Engl $\mathrm{J}$ Med. 1995;332:621-8

11. Dulloo AG, Jacquet J, Girardier L. Poststarvation hyperphagia and body fat overshooting in humans: a role for feedback signals from lean and fat tissues. Am J Clin Nutr. 1997;65:717-23.

12. Doucet E, Cameron J. Appetite control after weight loss: what is the role of bloodborne peptides? Appl Physiol Nutr Metab. 2007;32:523-32.

13. Polidori D, Sanghvi A, Seeley RJ, Hall KD. How strongly does appetite counter weight loss? Quantification of the feedback control of human energy intake. Obesity. 2016;24:2289-95.
14. Coutinho SR, With E, Rehfeld JF, Kulseng B, Truby H, Martins C. The impact of rate of weight loss on body composition and compensatory mechanisms during weight reduction: a randomized control trial. Clin Nutr. 2017.

15. Sumithran P, Prendergast LA, Delbridge E, Purcell K, Shulkes A, Kriketos A, et al. Long-term persistence of hormonal adaptations to weight loss. N Engl J Med. 2011;365:1597-604.

16. Nymo S, Coutinho SR, Jorgensen J, Rehfeld JF, Truby H, Kulseng B, et al. Timeline of changes in appetite during weight loss with a ketogenic diet. Int J Obes. 2017;41:1224-31.

17. Cummings DE, Weigle DS, Frayo RS, Breen PA, Ma MK, Dellinger EP, et al. Plasma ghrelin levels after diet-induced weight loss or gastric bypass surgery. N Engl J Med. 2002;346:1623-30.

18. Anton SD, Han H, York E, Martin CK, Ravussin E, Williamson DA. Effect of calorie restriction on subjective ratings of appetite. J Human Nutr Diet. 2009;22:141-7.

19. Wadden TA, Stunkard AJ, Day SC, Gould RA, Rubin CJ. Less food, less hunger: Reports of appetite and symptoms in a controlled study of a protein-sparing modified fast. Int $\mathrm{J}$ Obes. 1987;11:239-49.

20. Adam TC, Lejeune MP, Westerterp-Plantenga MS. Nutrientstimulated glucagon-like peptide 1 release after body-weight loss and weight maintenance in human subjects. $\mathrm{Br} \mathrm{J}$ Nutr. 2006;95:160-7.

21. Iepsen EW, Lundgren J, Holst JJ, Madsbad S, Torekov SS. Successful weight loss maintenance includes long-term increased meal responses of GLP-1 and PYY3-36. Eur J Endocrinol. 2016;174:775-84

22. Gregersen NT, Moller BK, Raben A, Kristensen ST, Holm L, Flint A, et al. Determinants of appetite ratings: the role of age, gender, BMI, physical activity, smoking habits, and diet/weight concern. Food Nutr Res. 2011;55:7028.

23. Asarian L, Geary N. Sex differences in the physiology of eating. Am J Physiol Regul Integr Comp Physiol. 2013;305:R1215-67.

24. Nordic Nutrition Recommendations. 2012: norden.org; 2014.

25. Scheers T, Philippaerts R, Lefevre J. Patterns of physical activity and sedentary behavior in normal-weight, overweight and obese adults, as measured with a portable armband device and an electronic diary. Clin Nutr. 2012;31:756-64.

26. Stubbs RJ, Hughes DA, Johnstone AM, Rowley E, Reid C, Elia $\mathrm{M}$, et al. The use of visual analogue scales to assess motivation to eat in human subjects: a review of their reliability and validity with an evaluation of new hand-held computerized systems for temporal tracking of appetite ratings. Br J Nutr. 2000;84:405-15.

27. Drapeau V, King N, Hetherington M, Doucet E, Blundell J, Tremblay A. Appetite sensations and satiety quotient: predictors of energy intake and weight loss. Appetite . 2007;48:159-66.

28. Rehfeld JF. Accurate measurement of cholecystokinin in plasma. Clin Chem. 1998;44:991-1001.

29. Benjamini Y, Hochberg, Y. Controlling the false discovery rate: a practical and powerful approach to multiple testing. J R Stat Soc. 1995; Series B (57):289-300.

30. Blackburn G. Effect of degree of weight loss on health benefits. Obes Res. 1995;3(Suppl 2):S211-6.

31. Ryan DH, Yockey SR. Weight loss and improvement in comorbidity: differences at 5\%,10\%,15\%, and over. Curr Obes Rep. 2017;6:187-94.

32. Heijboer AC, Frans A, Lomecky M, Blankenstein MA. Analysis of glucagon-like peptide 1: what to measure? Clin Chim Acta. 2011;412:1191-4.

33. Kuhre RE, Wewer Albrechtsen NJ, Hartmann B, Deacon CF, Holst JJ. Measurement of the incretin hormones: glucagon-like peptide-1 and glucose-dependent insulinotropic peptide. J Diabetes Complicat. 2015;29:445-50.

34. Bak MJ, Wewer Albrechtsen NJ, Pedersen J, Knop FK, Vilsboll $\mathrm{T}$, Jorgensen NB, et al. Specificity and sensitivity of commercially 
available assays for glucagon-like peptide-1 (GLP-1): implications for GLP-1 measurements in clinical studies. Diabetes Obes Metab. 2014;16:1155-64.

35. Drapeau V, Blundell J, Gallant AR, Arguin H, Despres JP, Lamarche B, et al. Behavioural and metabolic characterisation of the low satiety phenotype. Appetite. 2013;70:67-72.

36. Delgado-Aros S, Cremonini F, Castillo JE, Chial HJ, Burton DD, Ferber I, et al. Independent influences of body mass and gastric volumes on satiation in humans. Gastroenterology. 2004;126:432-40.

37. Park MI, Camilleri M. Gastric motor and sensory functions in obesity. Obes Res. 2005;13:491-500.

38. Geliebter A, Schachter S, Lohmann-Walter C, Feldman H, Hashim SA. Reduced stomach capacity in obese subjects after dieting. Am J Clin Nutr. 1996;63:170-3.

39. Verdich C, Toubro S, Buemann B, Lysgard Madsen J, Juul Holst J, Astrup A. The role of postprandial releases of insulin and incretin hormones in meal-induced satiety-effect of obesity and weight reduction. Int J Obes Relat Metab Disord. 2001;25:1206-14.

40. Chearskul S, Delbridge E, Shulkes A, Proietto J, Kriketos A. Effect of weight loss and ketosis on postprandial cholecystokinin and free fatty acid concentrations. Am J Clin Nutr. 2008;87:1238-46.

41. Doucet E, Laviolette M, Imbeault P, Strychar I, Rabasa-Lhoret R, Prud'homme D. Total peptide YY is a correlate of postprandial energy expenditure but not of appetite or energy intake in healthy women. Metabolism. 2008;57:1458-64.

42. Woo R, Kissileff HR, Pi-Sunyer FX. Elevated postprandial insulin levels do not induce satiety in normal-weight humans. Am J Physiol. 1984;247(4 Pt 2):R745-9.
43. Ochner CN, Barrios DM, Lee CD, Pi-Sunyer FX. Biological mechanisms that promote weight regain following weight loss in obese humans. Physiol Behav. 2013;120:106-13.

44. Greenway FL. Physiological adaptations to weight loss and factors favouring weight regain. Int J Obes. 2015;39:1188-96.

45. Sumithran P, Prendergast LA, Delbridge E, Purcell K, Shulkes A, Kriketos A, et al. Ketosis and appetite-mediating nutrients and hormones after weight loss. Eur J Clin Nutr. 2013;67:759-64.

46. le Roux CW, Patterson M, Vincent RP, Hunt C, Ghatei MA, Bloom SR. Postprandial plasma ghrelin is suppressed proportional to meal calorie content in normal-weight but not obese subjects. J Clin Endocrinol Metab. 2005;90:1068-71.

47. Ranganath LR, Beety JM, Morgan LM, Wright JW, Howland R, Marks V. Attenuated GLP-1 secretion in obesity: cause or consequence? Gut. 1996;38:916-9.

48. Meyer-Gerspach AC, Wolnerhanssen B, Beglinger B, Nessenius F, Napitupulu M, Schulte FH. Gastric and intestinal satiation in obese and normal weight healthy people. Physiol Behav. 2014;129:265-71.

49. le Roux CW, Batterham RL, Aylwin SJ, Patterson M, Borg CM, Wynne KJ, et al. Attenuated peptide YY release in obese subjects is associated with reduced satiety. Endocrinology . 2006;147:3-8.

50. Zwirska-Korczala K, Konturek SJ, Sodowski M, Wylezol M, Kuka D, Sowa P, et al. Basal and postprandial plasma levels of PYY, ghrelin, cholecystokinin, gastrin and insulin in women with moderate and morbid obesity and metabolic syndrome. J Physiol Pharmacol. 2007;58(Suppl 1):13-35.

51. Moehlecke M, Canani LH, Silva LO, Trindade MR, Friedman R, Leitao CB. Determinants of body weight regulation in humans. Arch Endocrinol Metab. 2016;60:152-62. 